alternating magnetic field (which is about $2,000 \mathrm{c} / \mathrm{s}$. in the latitude of Britain) produced by the precessing protons. The precessional frequency is directly proportional to the total field through the water sample. The advantages of the instrument are that calibration is unnecessary since the gyromagnetic ratio for the protons is known, and also that orientation of the bottle is not of importance provided its axis is not close to the direction of the Earth's field. This means that the object to be towed can be smaller than that of, for example, the towed fluxgate magnetometer. The body of the magnetometer used in the recent cruise was $5 \mathrm{ft}$. in length and $5 \mathrm{in}$. in outside diameter and was towed approximately $300 \mathrm{ft}$. astern. The electrical equipment necessary for the measurement of the precessional frequency was installed in the ship.

Sir Edward Bullard described the total force mag. netic measurements which were obtained with the nuclear spin magnetometer and with the fluxgate magnetometer on the recent cruise. One of the first interesting observations which resulted from these magnetic measurements was that which suggested that the Hercynian folding forming the Brittany Peninsula extended out to sea. A crossing of the line of its axis extended out over the continental shelf was obtained carly in the cruise and another on the return voyage to Plymouth, and both showed a considerable positive magnetic anomaly. Apart from this anomaly, the continental shelf and slope were magnetically smooth compared with the deeper water, where even in areas topographically flat considerable anomalies with a wave-length of the order of 12 miles were constantly observed. Even where there was some relief on the ocean floor it was not obvious if there was an association between these long wavelength anomalies and the topography. Superposed upon these long wave-length anomalies were those of about 2-miles wave-length which could sometimes be associated with topographic features.

Detailed magnetic surveys were made of the two seamounts where dan buoys were moored; although there appears to be some correlation between the depth and magnetic contours, it is not as good as would be expected if these seamounts, from a mag. netic point of view, consisted of lumps of magnetic material placed upon the sea floor.

Dr. J. C. Swallow described the deep water current measurement which had been obtained on the cruise. 'The method consists of loading aluminium alloy tubes so that at the surface they are slightly negatively buoyant. Since their compressibility is less than that of water, it can be arranged by suitable weighting that they reach a known depth where they possess neutral buoyancy. The tubes contain electrical sound-making devices which allow the floats to be followed for some days. Their position is determined relative to a fixed topographic feature of the sea floor. With the observations made on this cruise the current at 1,640 fathoms was found to be approximately $0.8 \mathrm{~cm} . / \mathrm{sec}$., or less than half $\mathrm{a}$ mile $\mathrm{a}$ day. The position of the observation was near the southeastern corner of the track of Discovery $I I$ and the depth of water about 2,800 fathoms. Dr. Swallow considers the magnitude of this bottom current to be so small that it may represent 'noise'; in order to obtain a more reliable estimate of the permanent current, observations would have to continue for a longer period than two days (see also Nature, 179, $1183 ; 1957)$.

Prof. W. F. Whittard spoke about a preliminary inspection he had made of the basalt boulders dredged from a seamount. These appeared at first sight to be weathered, since among other characteristics these rocks were exceptionally friable. It was difficult to understand how they could have got into this condition while resting on the floor of the deep ocean. Whittard also remarked that small pebbles dredged from the northern part of the Mid-Atlantic Ridge largely consisted of limestones and acidic igneous rocks. He expressed doubt if these could all have boen ice rafted.

Mr. A. R. Smith reviewed previous work on cosmic spherules derived from atmospheric dust collections and ocean sediments. He mentioned two recent theoretical indirect lines of investigation which suggest that there is an abundant supply of these spherules in space and that they can get through our atmosphere undamaged. He outlined an experimental programme which he is carrying out at Cambridge on the deep-sea cores obtained from the recent cruise. It is hoped that it will be possible to devise a positive method of identification of these spherules and to find out something about their density and composition, and their distribution in space.

In the discussion Dr. G. E. R. Deacon expressed satisfaction that Discovery $I I$ proved so versatile that the measurements described could be satisfactorily undertaken. It spoke well for the design of the ship that after nearly thirty years service she was still suited to modern techniques.

M. N. HILL

\title{
THE UNIVERSITY OF READING
}

\section{BY SIR JOHN WOLFENDEN, C.B.E. \\ Vice-Chancellor}

\begin{abstract}
HE University of Reading is on the move, literally as well as metaphorically. 'The new building in Whiteknights .Park which Her Majesty 'The Queen, accompanied by Prince Philip, recently opened is the first outward and visible sign of an imaginative and far-reaching plan of development. When this plan is completely realized the University of Reading will have a material equipment which will not easily be surpassed by any other University in Britain.

'The original home of the University Extension College was in the heart of the town of Reading.
\end{abstract}

It was a cluster of munieipal buildings (some of which have to-day become part of the Police Station) provided by the Borough Council to meet the needs of adult education as it was understood in the 1890's. The site was cramped, the buildings quickly became inadequate, and the atmosphere was inappropriate to the academic ambitions which the principal, Dr. W. M. Childs, and his colleagues properly cherished.

The energetic enthusiasm of Childs and the generous faith of Alfred Palmer made an irresistible combination. Between them they brought it about 


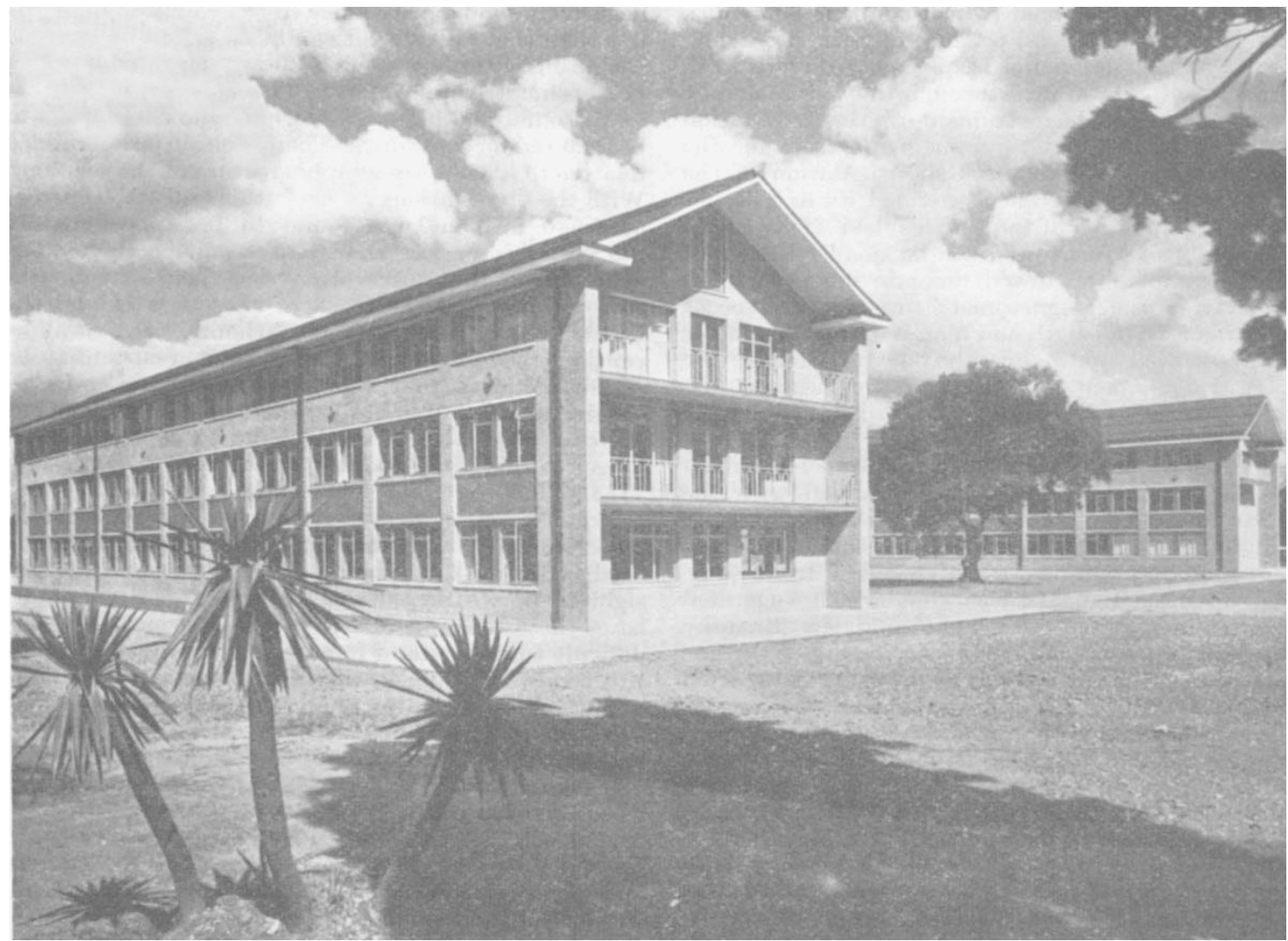

Fig. 1. Faculty of Letters : Main Building

that the College entered into possession of a substantial area of Palmer property, and to it the College moved in 1906. This London Road site had (and has) many attractions. Few of those who drive through Reading on their way from London to Bath realize either that a row of modest Georgian houses is the frontage of the University of Reading or that immediately behind those houses there are gardens and trees of a beauty and freshness quite unexpected thirty yards from a trunk road. Yet it is here that the University has lived, in simple dignity, for fifty years. The buildings, the open cloisters and the gardens themselves have made their impression on generations of students and have rightly earned their affection.

But year by year the pressure on space has in. exorably increased. For Childs "There was room here to spread ourselves, and to house our work without overcrowding'". But even by 1939, though, by com. parison with other universities, Reading was still small, it was elear that the London Road site was no longer adequate. New departments and new needs had encroached on the lawns of the old gardens, and proper development was cramped for lack of space. The post-war demands for university expansion brought these difficulties to a head. It was simply impossible to meet them in surroundings which had been palatial for an infant college but were quite insufficient for a thriving and growing University.

In 1947 an opportunity arose, with dramatic unexpectedness. It was boldly seized, by the foresight of the then vice-chancellor, Sir Frank Stenton, and the University Council of the day. Whiteknights
Park, an estate of three hundred acres on the southern fringe of the town, came into the market. The planning authorities, which had scheduled it as a permanent open space, generously agreed that it should be used for University development, and the first steps in a comprehensive scheme were taken. The University Grants Committee and the Treasury made their indispensable contribution, and the practical problems of planning were taken in hand. Architects were appointed, a site-plan was drawn up, and the University set itself the exciting task of working out its order of march from the London Road to Whiteknights Park.

It was inevitable that there should be delays and frustrations. Priorities change even in a period of ten years, specially when those ten years are as eventful as the last decade has been, both in public affairs at large and in the affairs of the universities of Great Britain. But on two important points there has been no departure from firmly held policies. First, the University is resolved that the beauty of Whiteknights Park should not be damaged, but should be positively enhanced, by the building of a university on it. The estate is a typical piece of English parkland, with pleasant contours, admirable trees, an interesting lake, and an attractive air of naturalness. The University is very conscious of its beauty, and of the obligation to pay full regard to it. The precise siting of buildings has been done in such a way as to preserve individual trees and to make the most of the existing background. There is no intention to sweep away what is already there and to start from a tabula rasa. Hundreds of new trees 


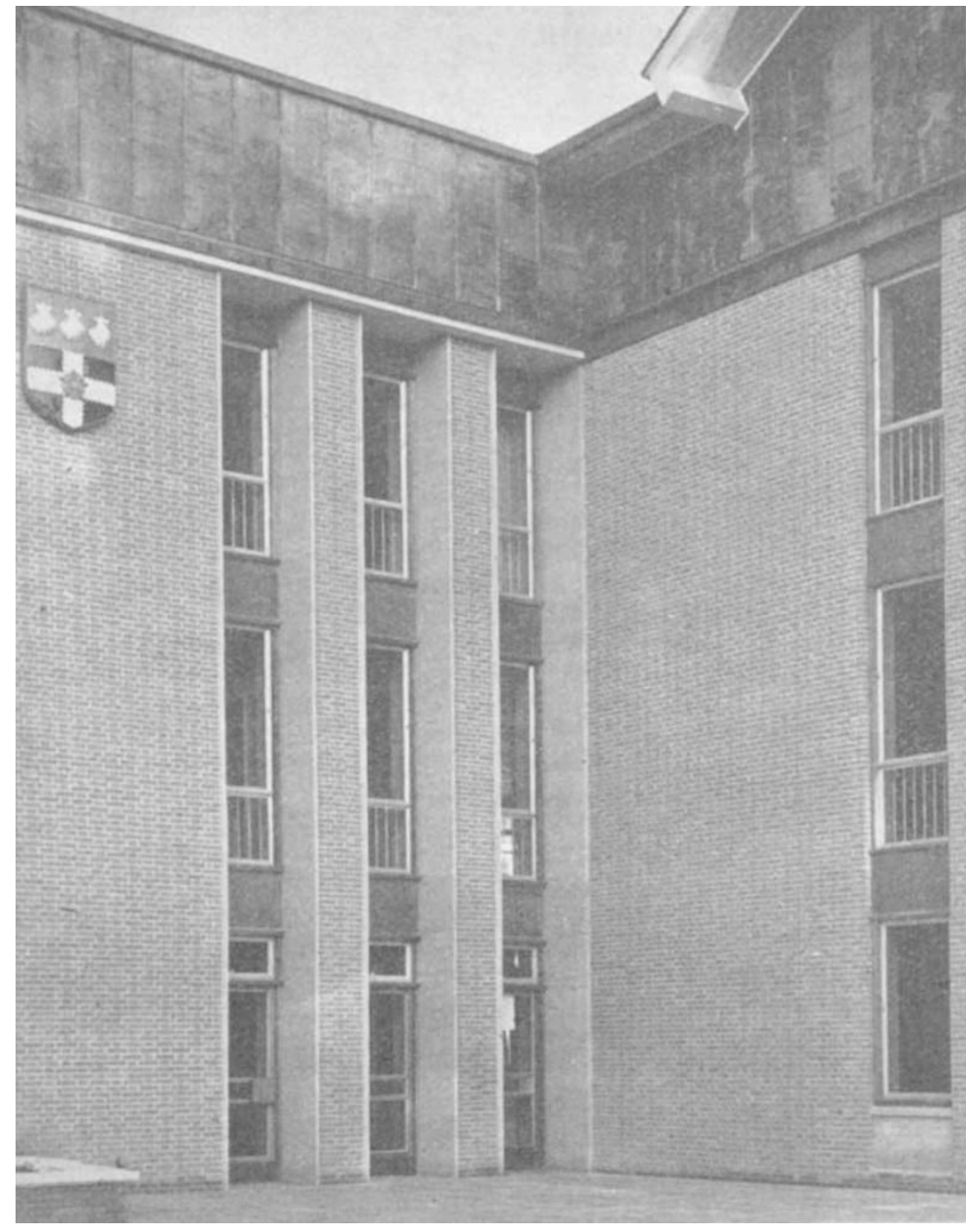

Fig. 2. Faculty of Letters: Main Entrance

In the autumn of 1954 Sir Frank Stenton cut the first turf on the site, and as he did so the first machines rolled on to the first building area. In May of 1955, Lord Templewood laid the foundation stone on a typical summer day of hail, thunder and torrential rain. On March 22, 1957, Her Majesty formally opened the first new building, in brilliant sunshine.

This building houses the Faculty of Letters. It concentrates the Departments of Philosophy, Classies, English, Italian, German, Political Economy, French, Modern History and Mathematics. Geography and Psychology, Departments which have one leg in the Faculty of Letters and one in the Faculty of Science, remain for the present with their scientific colleagues on the old site. There are common rooms, for academic staff and for students, lecture rooms, two departmental museums, and a private room for each member of the academic staff. The building contains a small theatre, inaugurated in March with a presentation of "King Lear".

It is a three-story building with a total area of approximately 65,000 $\mathrm{sq} . \mathrm{ft}$. It is a steel-framed structure with hollow block concrete floors and a low-pitched copper-covered roof. The external walls are built in Buckinghamshire Brown-Grey facing bricks, and the window panels are faced in Verde Oliva and San Stefano marble. The window frames are aluminium, set in African mahogany sub-frames.

have been planted-many of them a gift from the chancellor, Lord Templewond.

The Univer'sity's second determination is that its organic life shall not be split in two by the gradual transfer from one site to another. Clearly, a move of this kind will take many years to complete, and during that time part of the University will be in Whiteknights Park while a diminishing part stays in the London Road. This problem is not unfamiliar in the history of university development, and there are lessons which Reading is gratefully learning from its sisters. But both its senior members and its student body are alive to the dangers of schizophrenia (or schizosomatosis) and resolved that topographical separation shall not mean disruption or divorce. The actual distances involved are not immense, by the standards of towns bigger than Reading ; three-quarters of a suburban mile is not a sabbath day's journey.

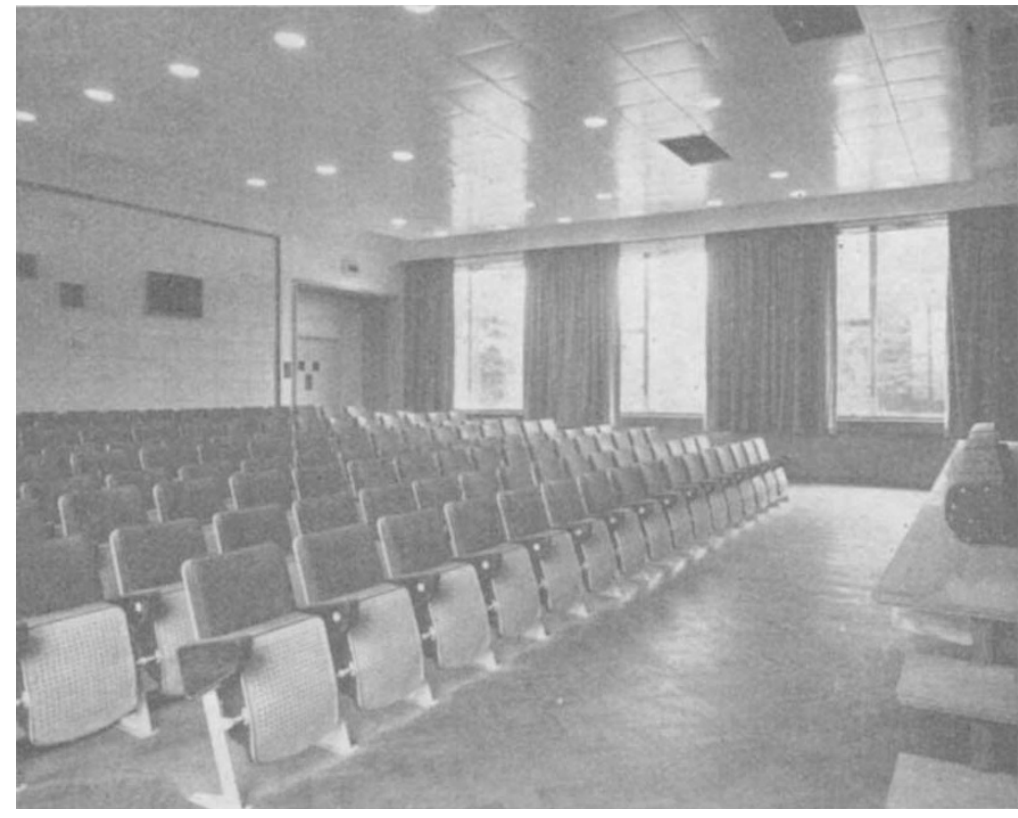

Fig. 3. Faculty of Letters: Theatre 
Internally, the wall finish is mainly fairface brickwork, Uxbridge Flint facing bricks being used for this purpose. Wood block flooring is extensively employed, although to reduce noise the corridors are finished in 'Korkoid'. The main entrance hall and staircase are paved in 'Travertine', and the columns in this area are faced in San Stefano and Ashburton marble.

The building is heated by means of Frenger Acoustic heated ceiling, a comparatively recent development consisting of perforated aluminium panels clipped to a continuous grid of heating pipes. The lighting throughout is by tungsten fittings, with the exception of the Classics Museum, which has fluorescent ceiling fittings and concealed tubes in the showcases.

The Departments of the Faculty of Letters are housed in the two long wings, each served by a subsidiary staircase. Nine lecture rooms are grouped in the centre block. Of these, seven are arranged to seat fifty students each, one to seat seventy-five, and one to seat a hundred. This last has a raked floor, and a projection room, which also serves the lecture room accommodating seventy-five.

In addition, on the first floor there is a fully equipped theatre with seating for 173 persons. This is approached directly from the main entrance hall and staircase. Underneath this theatre, on the ground floor, the main lavatory and cloakroom accommodation is grouped.

All the lecture rooms, and certain of the department rooms, are equipped with revolving or fixed blackboards, and in many of them a pull-down projection screen is also fitted. Special provision has been made throughout the building for the use of portable blackboards and display boards.

The two main common rooms, one for the academic staff and one for students, are located on the groundand second-floors respectively, each with kitchen facilities. The academic staff room opens on to a paved terrace.

The architects are Messrs. Easton and Robertson and the quantity surveyors, Messrs. Hamilton $H$. Turner and Son. Consultants for the heating services, drainage work and landscape work are, respectively, Messrs. Donald Smith, Seymour and Rooley, Mr. Daniel Longden and Miss Mary Braendle. The builders are Taylor Woodrow Construction, Ltd.

By a triumphant combination of imagination and practical skill this quite large building sits comfortably and almost unobtrusively in its parkland setting. From every window in it there are trees and sky to be seen, and inside it there is an agreeable air of spaciousness and quiet. It succeeds in being friendly and domestic without losing dignity. The develop- ment of the Whiteknights Park estate has got off to a good start.

But, of course, this is only the first move. It has set the tone and pace, but it is really only a foretaste of the whole that is to be. The next moves promise to be no less exciting and no less arduous. Plans are well advanced for the two next buildings. They are to be a Hall of Residence and the Department of Physics.

It is natural that, in Reading especially, a new Hall of Residence should stand high on the priority list. On grounds of policy and of practical need, Reading has from the first developed the residential system as one of its distinguishing characteristics, and additional residential accommodation was a serious need even before the latest demands for expansion were made.

A new building for the Department of Physics is an equally urgent need. For many years the Department has conducted its multifarious activities on two separate sites, and the consequent waste of time and energy has for long been almost intolerable. To concentrate the Department in a new building in Whiteknights Park will ease this strain considerably, and will also be an important step towards removing one of the serious obstacles to an increased output of scientists and technologists.

Some time soon, the Library will have to move. Distances may not be great, but there is something rather startling in having a Faculty of Letters in one place and the University Library three-quarters of a mile away. The sudden bright thought of the lecturer, the immediate necessity for checking a reference, and, especially, the fostering of the habit of meditative reading, all demand that the gap in space between the student and the main body of his tools must be bridged as soon as can possibly be.

Other Departments of the Faculty of Science stand high in the queue. The Department of Geology is one, encouraged by handsome benefactions from the oil industry, to assist in the development of studies in sedimentology. Zoology and Microbiology, too, need much more space than is available on the London Road site if they are to make their proper contribution to national needs and to provide the required teaching for the Faculty of Agriculture.

So there will be no peace for the planners for many years yet. The heartening elements in the situation are the liveliness and enterprise of the Departments concerned, the understanding and concern of the University Grants Committee and the sensitive imagination of the architects. How long it will be before the whole of the University is safely housed in Whiteknights Park nobody can possibly know. But the move has begun, and hopes are high.

\section{OBITUARIES}

\section{Prof. K. F. Bonhoeffer}

THE death of Karl Friedrich Bonhoeffer on May 15 at the age of fifty-eight deprived Germany of her foremost physical chemist. He was a member of a distinguished family: his father was professor of psychiatry at Berlin; his brother, who died some years ago, shared with Niemöller the lasting fame which came to those who championed the cause of the Church under Nazi tyranny. He served in the infantry in the First World War and was wounded in 1918. He suffered much also during the Second World War in another way.

Bonhoeffer's academic career began at the Universities of Tübingen and Berlin, where he graduated under Nernst and later became for seven years Haber's assistant at the Kaiser Wilhelm Institute in Dahlem. He successively occupied the chairs of physical chemistry at the Universities of Frankfurtam-Main (1930), Leipzig (1934) and Berlin (1947), where he was also a director of the Kaiser Wilhelm 